\title{
A survey of wheelchair use by paraplegic individuals in Japan. Part 2: Prevalence of pressure sores
}

\author{
${ }^{1}$ Tadashi Sumiya, Kenji Kawamura ${ }^{2}$, Akihiro Tokuhiro ${ }^{3}$, Hideo Takechi $^{3}$ and Hajime Ogata ${ }^{4}$ \\ ${ }^{1}$ Rosai Rehabilitation Engineering Center, 1-10-5 Komei, Minato-ku, Nagoya, 455; ${ }^{2}$ Department of Physical Therapy, \\ School of Health Science, Kibi International University, 8 Igamachi, Takahashi, 716; ${ }^{3}$ Kibikogen Rehabilitation \\ Center, 7511 Nagasaka, Yoshikawa, Kayo-cho, Jobo-gun, 716-12; ${ }^{4}$ Department of Rehabilitation Medicine, University \\ of Occupational and Environmental Health, 1 Iseigaoka, Yahata Nishi-ku, Kita-kyushu, 807, Japan
}

\begin{abstract}
A cross-sectional survey was done to clarify the incidence of pressure sores in 218 selfsupported Japanese paraplegic patients and to determine effective measures for prevention. The majority of patients $(85.7 \%)$ had previous pressure sores, and $46.3 \%$ had undergone multiple surgeries. Some patients $(17.9 \%)$ were still suffering from persistent sores which commonly developed at the ischial tuberosities, suggesting insufficiency of self-care practice during wheelchair activities. Sensory disturbance over the seating surface, urinary incontinence, and general complications were seen in $85.8 \%, 49.5 \%$, and $18.8 \%$ of total subjects, respectively. They were seen as risk factors for pressure sores, but only urinary incontinence clearly increased the current pressure sore prevalence. Nevertheless, both self-care practice and sports activities, seen in $85.3 \%$ and $36.2 \%$ of total subjects, respectively, contributed to greatly reduce the incidence. A patient education system including acquisition of basic knowledge and proper technique should be established to promote effective prevention of pressure sores in Japan.
\end{abstract}

Keywords: spinal cord injury; pressure sores; prevalence; prevention

\section{Introduction}

The first half of this report focused on the characteristics of wheelchair cushions used by Japanese paraplegic patients. The second half examined the incidence of pressure sores and various physical factors contributing to their occurrence and prevention in the same sample as Part 1, to determine the most effective measures for prevention of pressures sores.

\section{Subjects and methods}

The subjects surveyed and the methods used were the same as in Part 1. In addition to wheelchair cushions, the subjects were interviewed directly about pressure sores and physical condition. Pressure sores included past history and current status of pressure sores, anatomical site, and previous surgery. The current pressure sore incidence was expressed as number of patients per 100 population (\%). The survey of physical condition consisted of risk factors and preventive factors (therapeutic treatments) for pressure sores. Risk factors included sensory disturbance over the seating surface, urinary incontinence, and general complications; preventive factors included self-care practice and sport activities.

Correspondence: T Sumiya
General complications were defined from questions regarding the medical control of physical condition. All diseases were recorded regardless of the degree of symptoms or contribution to pressure sore development.

Furthermore, the influence of these factors on the current pressure sore prevalence was statistically analyzed by using the $\chi^{2}$ test for independence $(P<0.01)$.

\section{Results}

The numbers of patients with previous and current pressure sores are shown in Table 1. There were 143 patients $(65.6 \%)$ in the past and 39 patients in the present (the current pressure sore incidence: 17.9\%). The most common site was the ischial tuberosities, but the sacrum, the coccyx and the greater trochanters were also common locations for pressure sore development. A past history of pressure sores over the ischial tuberosities was recorded in 81 patients (43.3\% of 187) and pressure sores had persisted at the same location in 18 patients $(46 \%$ of 39$)$.

Surgery was performed in 101 patients $(46.3 \%$ of all patients, 218); $62(61.4 \%)$ of them had experienced two or more surgical interventions, that is, one patient underwent surgery 2.6 times on an average. 
Table 2 summarizes the physical condition of subjects. A considerable number of risk factors for pressure sores were seen. The majority of patients $(187,85.8 \%)$ showed sensory disturbance over the seating surface. Half of the patients $(108,49.5 \%)$ were suffering from urinary incontinence. Approximately one-fifth of total subjects $(41,18.8 \%)$ had general complications; hypertension, urinary infection, and mild liver dysfunction were very frequently observed, but only a low rate of diabetes mellitus which is closely related to tissue damage and infection was recorded.

Therapeutic treatments employed to prevent pressure sores were seen in a large number of patients; selfcare management was practiced by $186 \quad(85.3 \%)$ patients and $79(36.2 \%)$ patients were engaging in sport activities. Attention should be paid to the fact that as many as $28(71.8 \%)$ of 39 patients with current pressure sores were practicing self-care management.

Table 1 Previous and current pressure sores

\begin{tabular}{lcc}
\hline Anatomical sites & \multicolumn{2}{c}{ Number of patients } \\
Previous & Current \\
\hline Ischial tuberosities & $81(43.3)$ & $18(46.2)$ \\
Sacrum & $62(33.1)$ & $13(33.3)$ \\
Coccyx & $19(10.1)$ & $4(10.3)$ \\
Greater trochanters & $11(5.9)$ & $2(5.1)$ \\
Others & $14(7.5)$ & $2(5.1)$ \\
Duplicate total & 187 & 39 \\
$\quad$ Single lesion & 112 & 39 \\
Multiple lesion & 31 & 0 \\
Real total & 143 & 39 \\
\hline
\end{tabular}

The total number of 187 with previous pressure sores contains duplication because 31 patients had multiple sites of pressure sore development. ( ) Indicates percentages to each of 187 and 39. Others include the medial and lateral malleoli, the feet, the heads of fibula, the thighs, and so forth

Table 2 Physical condition

\begin{tabular}{lc}
\hline $\begin{array}{l}\text { Factors for } \\
\text { pressure sore development }\end{array}$ & $\begin{array}{c}\text { Number of } \\
\text { patients }\end{array}$ \\
\hline Risk factors & \\
(1) Sensory disturbance over & $187(85.8)$ \\
the seating surface & $108(49.5)$ \\
(2) Urinary incontinence & $41(18.8)$ \\
(3) General complications & $7(3.2)$ \\
(a) Hypertension & $7(3.2)$ \\
(b) Urinary infection & $6(2.8)$ \\
(c) Liver dysfunction (mild) & $3(1.4)$ \\
(d) Diabetes mellitus & $3(1.4)$ \\
(e) Renal dysfunction (mild) & $15(6.9)$ \\
(f) Others & $186(85.3)$ \\
Preventive factors & $79(36.2)$ \\
(1) Self-care practice & \\
(2) Sports activities &
\end{tabular}

( ) Indicates percentages to the total number of patients, 218
Table 3 shows the number of patients with or without current pressure sores divided into absence and presence of various physical factors; Figures 1 and 2 display these values as percentages.

Figure 1 shows the influence of three risk factors on the current pressure sore prevalence. Only urinary incontinence showed a strong association with the prevalence; the presence of urinary incontinence tripled the prevalence from $9.1 \%$ to $26.9 \%$.

Figure 2 shows the influence of preventive factors on the current pressure sore prevalence. Self-care practice reduced the incidence from $34.4 \%$ to $15.1 \%$ and sports activities also reduced it from $23.0 \%$ to $8.9 \%$.

\section{Discussion}

The actual incidence of pressure sores in paraplegic patients who live independently in Japan is not well documented. Various reports from Western countries have described incidences of pressure sores among spinal cord injury patients of $25-85 \%,{ }_{1}^{1} 19 \%\left(\mathrm{C}_{1}-\mathrm{C}_{7}\right.$ level) $-45 \%\left(\mathrm{~T}_{1}-\mathrm{T}_{10}\right.$ level $){ }^{2}$ and $30 \%{ }^{3}$

The large number of patients with previous pressure sores in our survey $(143,65.6 \%)$ can be attributed partly to poor medical care given in hospital during the acute stage of trauma, and partly to insufficient self-care management. However, the patients with current pressure sores $(39,17.9 \%), 71.8 \%$ of whom were practicing self-care management for prevention, resulted from insufficient knowledge or improper management technique. The ischial tuberosities were the most favorite site of pressure sore development because they often create the maximum pressure on the seating surface. ${ }^{2}$

The high population $(46.3 \%)$ of patients with a history of surgery indicates insufficient appropriate action taken to prevent the progression of sores from mild to severe. Moreover, the frequent surgery (2.6 times for one patient on an average) suggests a lack of awareness that pressure sores can cause considerable problems including life-threatening complications. ${ }^{4}$

Table 3 Number of patients divided in the absence/presence of current pressure sores and various physical factors

\begin{tabular}{lccc}
\hline \multirow{2}{*}{ Physical factors } & & \multicolumn{2}{c}{ Current pressure sores } \\
Absent & Present \\
\hline Sensory disturbance over & Absent & 26 & 5 \\
the seating surface & Present & 153 & 34 \\
Urinary incontinence & Absent & 100 & 10 \\
& Present & 79 & 29 \\
General complications & Absent & 145 & 32 \\
& Present & 34 & 7 \\
Self-care practice & Absent & 21 & 11 \\
& Present & 158 & 28 \\
Sports activities & Absent & 107 & 32 \\
& Present & 72 & 7 \\
\hline
\end{tabular}



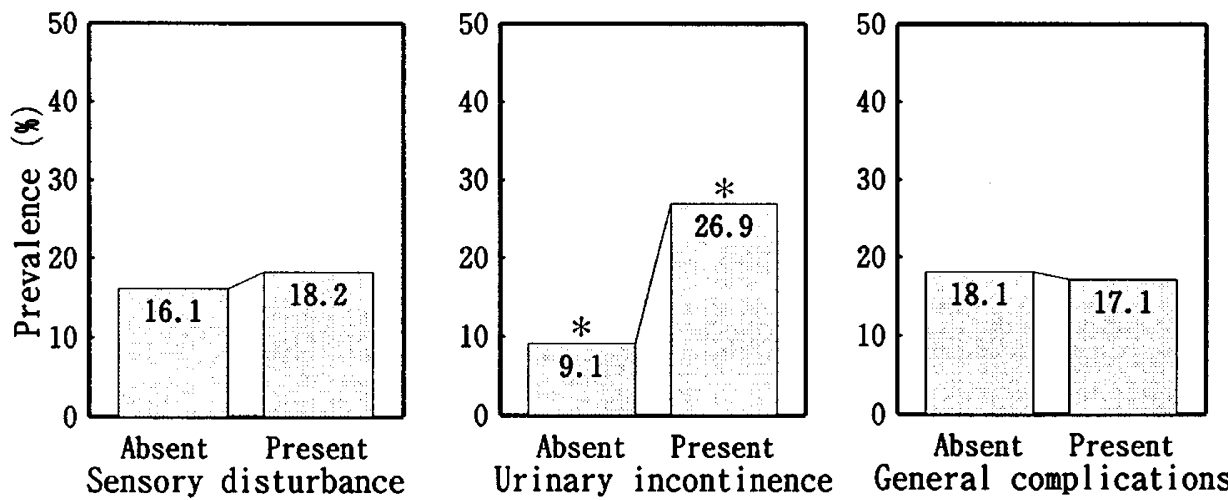

Figure 1 The influence of risk factors on the current pressure sore prevalence. *Significant difference at $P<0.01$ level
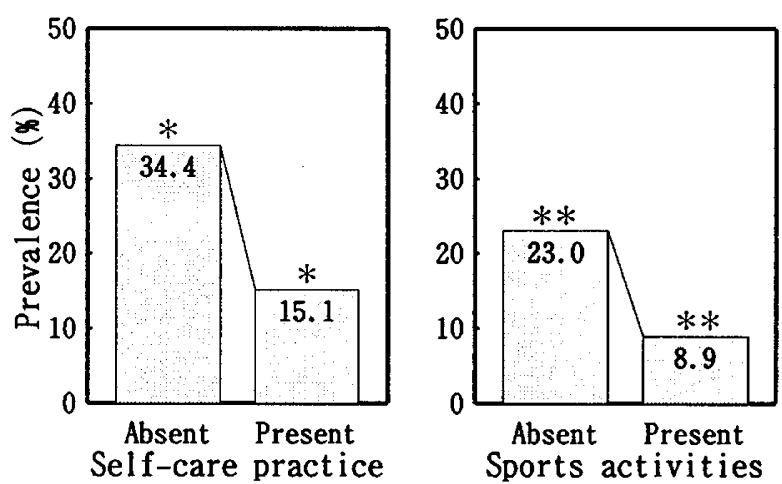

Figure 2 The influence of preventive factors on the current pressure sore prevalence. $* * *$ Significant difference at $P<0.01$ level

Although ischial pressure sores tend to recur frequently, ${ }^{5}$ sufficient education of the patients can help them recognize the necessity of self-care management and acquire proper techniques.

Pressure sore prevention requires an understanding of etiology, risk factors, complications, medical management, and prevention. ${ }^{6-8}$ Pressure sore preventive techniques consist of proper positioning 9 and transference of weight, ${ }^{10}$ pressure-relieving motion, ${ }^{11}$ and effective wheelchair cushioning. ${ }^{2}$

Although impaired sensation unquestionably induces pressure sores in spinal cord injury patients, ${ }^{4}$ the current pressure sore prevalence showed no difference between absence or presence of sensory disturbance. This may have resulted from insufficient physical examinations of the buttock areas.

It has been widely accepted that urinary incontinence promotes pressure sore development by causing excoriation and maceration of the skin, ${ }^{12}$ and our result coincides with this opinion. Since the current pressure sore prevalence tripled in the presence of urinary incontinence, the importance of urological management cannot be overemphasized.

General complications largely included diseases irrelevant to current pressure sore development such as hypertension and mild liver dysfunction. Moreover, such diseases relevant to pressure sore development as urinary infection and diabetes mellitus were under regular control at outpatient clinics. For these reasons, the current pressure sore prevalence showed no changes in the presence of general complications.

The marked reduction of pressure sore prevalence with self-care practice proved its important role in the prevention of pressure sores. A greater effect can be expected by showing patients basic information and proper techniques for pressure sore prevention systematically as a medical service. ${ }^{3}$ Various textbooks written for this purpose can be applied for teaching. 12,13

Sports activities are also useful to reduce pressure sore prevalence largely. By engaging in sports, spinal cord injury patients can not only prevent disuse, but improve respiratory/circulatory functions and energy consumption, ${ }^{14}$ and get rid of stress. Moreover, sports activities activate their entire lives, motivating regular self-care management. Therefore, sports activities should be highly recommended in patient education.

Based on the above considerations, we believe selfcare practice is essential for paraplegic patients to effectively prevent pressure sores. A patient education system including acquisition of basic knowledge and proper technique should be established as a medical service to encourage and motivate them to undertake regular self-care management, in combination with the wheelchair cushion management described in Part 1. In addition to this survey, a follow-up survey should also be done to observe changes in pressure sore prevalence among Japanese paraplegic patients.

\section{Conclusion}

A survey of the same sample as Part 1 revealed many patients with a history of pressure sores $(143,65.6 \%)$ and high incidence of current pressure sores (39, $17.9 \%$ ) with ischial tuberosity sores being predominant. Moreover, approximately half of the patients $(101,46.3 \%)$ had undergone surgery, including multi- 
ple surgeries in $61.4 \%$, suggesting insufficient self-care practice.

Risk factors for pressure sores including sensory disturbance over the seating surface, urinary incontinence, and general complications were seen in $85.8 \%$, $49.5 \%$, and $18.8 \%$ of total subjects, respectively. The current pressure sore prevalence tripled in association with urinary incontinence.

Self-care practice and sports activities, as contributing factors to pressure sore prevention, were seen in $85.3 \%$ and $36.2 \%$ of total subjects, respectively. Both markedly reduced the current pressure sore prevalence.

A patient education system including acquisition of basic knowledge and proper technique for self-care management, in combination with a wheelchair cushion management system, should be established as a medical service to encourage and motivate paraplegic patients in Japan to effectively prevent pressure sores.

\section{Acknowledgements}

These surveys, for the two papers were supported by the Japanese Labor Welfare Corporation. The authors would like to acknowledge the role of Dr Akio Nakajima, Dr Torakichi Inoue, Dr Kimio Shimada, and Dr Osamu Yoshimura, who contributed greatly to the present data collection of this survey.

\section{References}

1 Dinsdale SM. Decubitus ulcers: role of pressure and friction in causation. Arch Phys Med Rehabil 1974; 55: 147-152.

2 Noble PC. The prevention of pressure sores in persons with spinal cord injuries. World Rehabilitation Fund: New York, 1981.

3 Staas WE, Cioschi HM. Pressure sores - a multiple approach to prevention and treatment. West J Med 1991; 154: 539-544.

4 Yarkony GM. Pressure ulcers: a review. Arch Phys Med Rehabil 1994; 75: 908 -917.

5 Berry RB. The late results of surgical treatment of pressure sores in paraplegics. British J Surg 1980; 67: 473-474.

6 Ferguson-Pell MW, Wilkie IC, Reswick JB, Barbenel JC. Pressure sore prevention for the wheelchair-bound spinal cord injury patient. Paraplegia 1980; 18: $42-51$.

7 Rueler JB, Cooney TG. The pressure sore: pathophysiology and principles of management. Ann Intern Med 1981; 94: 661-666.

8 Krouskop TA, Noble PC, Garber SL, Spencer WA. The effectiveness of preventive management in reducing the occurrence of pressure sores. J Rehabil Res Dev 1983; 20: 74-83.

9 Zacharkow D. Wheelchair posture and pressure sores. Charles C Thomas: Springfield, 1984

10 Hobson DA. Comparative effects of posture on pressure and shear at the body-seat interface. $J$ Rehabil Res Dev 1992; 29: 21 31 .

11 Henderson JL, Price SH, Brandstater ME, Mandac BR. Efficacy of three measures to relieve pressure in seated persons with spinal cord injury. Arch Phys Med Rehabil 1994; 75: 535-539.

12 Bedbrook GM (ed). Lifetime care of the paraplegic patient. Churchill Livingstone: New York, 1985.

13 Phillips L, Ozer MN, Axelson P, Chizeck H. Spinal cord injury A guide for patients and family. Raven Press Books: New York, 1987.

14 Zwiren LD, Bar-Or O. Responses to exercise of paraplegics who differ in conditioning level. Med Sci Sports 1975; 7: 94-98. 